\title{
FRECUENCIA DE Brucella sp. EN PORCINOS, PROCEDENTES DE GRANJAS TECNIFICADAS Y NO TECNIFICADAS, BENEFICIADOS EN DOS MATADEROS DE LIMA
}

\author{
Diana Farro R. ${ }^{1}$, Néstor Falcón P. ${ }^{2}$, Alberto Manchego S. ${ }^{3}$ y Hermelinda Rivera G..$^{3,4}$
}

\section{A BSTRACT}

The objective of this study was to determine the frequency of Brucella sp in pigs from well managed and poor managed farms ot the Lima valley, Peru. For this purpose, blood samples of pigs from well managed $(n=222)$ and poor managed $(n=218)$ forms were collected at two slanghterhouses. Animals were of both sexes and older than 4 months of age. Antibodies against Brucella sp. were detected by the Rose Bengal test (RB) and Complement Fixation (CF) test. The frecuency of Brucella sp. was $4.77 \pm 1.81 \%$ in the studied population. The frequency of Brucella sp. in well and poor managed pig farms were $2.25 \pm 1.47 \%(5 / 222)$ and $7.34 \pm 3.34 \%(16 / 218)$ respectively, when RB test was used. However, only $2.75+1.76 \%(6 / 218)$ in poor managed farms had antibodies against Brucella sp when using the CF test. None of the animals from well managed farms resulted positive by $\mathrm{CF}$ test. This study indicate the presence of brucellosis in poor managed pigs farms, representing a risk for the pig industry and public health.

Key words: pigs, Brucella sp., Rose Bengal, Complement Fixation test, antibodies, management system

\section{REstuen}

El presente estudio tuvo como objetivo determinar la frecuencia de Brucella sp. en porcinos procedentes de granjas con crianza tecnificada y no tecnificada, que fueron beneficiados en dos mataderos de Lima. Con este fin se tomaron muestras de sangre de porcinos de ambos sexos y mayores de cuatro meses, procedentes de granjas de crianza tecnificada $(n=222)$ y no tecnificada $(n=218)$, para la detección de anticuerpos contra Brucella sp. mediante la prueba de Rosa de Bengalả como prueba tamiz y Fijación de Complemento (FC) como prueba confirmatoria. El $2.25 \pm 1.47 \%(5 / 222)$ y el $7.34 \pm 3.34 \%$ $(16 / 218)$ de las muestras procedentes de crianza tecnificada y no tecnificada, respectivamente, tuvieron anticuerpos contra Brucella sp. mediante la prueba de Rosa de Bengala; pero únicamente el $2.75 \pm 1.76 \%(6 / 218)$ de muestras pertenecientes a los animales de crianza no tecnificada resultó positivo a la prueba de FC. No se detectaron animales serorreactores en las granjas tecnificadas muestreadas. Estos resultados demuestran la presencia de la Brucella sp. en porcinos de crianza no tecnificada constituyendo un riesgo para la crianza porcina y la salud pública.

Palabras clave: porcinos, Brucella sp, Rosa de Bengala, Fijación de Complemento, anticuerpos, sistema de manejo

'Práctica privada

${ }^{2}$ Laboratorio de Medicina Preventiva, FMV-UNMSM

${ }^{3}$ Laboratorio de Microbiología y Parasitología, FMV-UNMSM

${ }^{4}$ E-mail: hriverag@vet.unmsm.edu.pe 


\section{INTRODUCCIÓN}

La población porcina del Perú es de aproximadamente 2.2 millones de animales, de los cuales el $46.8 \%$ se encuentra en la costa en manos de porcicultores que utilizan una crianza con alta tecnología. El resto de la población pertenece a pequeños criadores de la sierra y selva y a los criadores de parques porcinos ubicados en los alrededores de las grandes ciudades como Lima (INEI, 1995). La mayoría de estos últimos son criados en forma libre o con un escaso nivel tecnológico, sobre todo, en el aspecto sanitario, donde enfermedades como el cólera porcino son prevalentes (Ríos et al., 1997), y otras, como la brucelosis, podrían estar presentes.

La brucelosis es una zoonosis de distribución mundial, producida por una bacteria del género Brucella, que afecta a todas las especies de animales domésticos y silvestres (Wrathall et al., 1993). El género Brucella comprende 7 especies: B. abortus, melitensis, suis, canis, ovis, neotomae, y maris; siendo las cuatro primeras de importancia en salud pública. Las brucellas son organismos intracelulares obligatorios y resistentes a la fagocitosis, por lo que pueden vivir y multiplicarse en los leucocitos polimorfonucleares y macrófagos; de allí se distribuyen a los órganos linfoides formando granulomas con células epitelioides, linfocitos y plasmocitos, y con posterior caseificación en el caso de $B$. abortus, y con posible caseificación en $B$. suis (Alton et al., 1998; Bercovich, 1988). Las cepas de Brucella virulentas forman colonias lisas y transparentes en cultivo, y generalmente tienden a cambiar a la forma rugosa que es avirulenta (Corbel, 1997).

La Brucella sp. muestra un especial tropismo por las membranas fetales y el tejido mamario, por lo que su difusión se hace principalmente durante el parto de animales enfermos o durante el aborto, donde se elimina gran cantidad de bacterias al medio ambiente (Nicoletti, 1980; Sangari y Agüero,
1996; Dájer et al., 1997). La transmisión de la $B$. suis en el cerdo es por vía digestiva o respiratoria, por abrasiones de la piel, por conjuntiva, o durante la monta. Sin embargo, no se observa una predilección por localizarse en el útero o la ubre, sino que la bacteria se encuentra en todos los tejidos produciendo una enfermedad similar a la fiebre ondulante producido por la $B r$ melitensis o Br. abortus en el hombre. Se observa una invasión generalizada inicial, y una bacteriemia que puede perdurar hasta dos meses (OPS, 1986; Samartino, 2001; Alton et al., 1998; Bercovich, 1998).

La enfermedad actualmente alcanza su mayor importancia como un peligro de contagio a las personas que manipulan carne de cerdo (personal de mataderos, y en menor grado veterinarios y ganaderos). En 1992 se reportaron 18 casos de brucelosis en trabajadores de una planta de matanza y procesamiento de carne de cerdo en Carolina, EE.UU., lo que demuestra el riesgo de contraer brucelosis causada por B. suis. (Trout et al., 1995).

A pesar de la importancia de la brucelosis porcina, noexiste información actualizada en el país acerca de su situación epidemiológica. Por esta razón, el presente estudio tuvo como objetivo determinar la frecuencia de la brucelosis en porcinos procedentes de crianza tecnificada y no tecnificada que fueron beneficiados en dos importantes mataderos de Lima, y de esta manera contribuir a una mejor comprensión de la epidemiología de la enfermedad en nuestro país.

\section{Materiales y Métodos}

\section{Animales}

Se utilizaron cerdos que fueron beneficiados en dos mataderos de Lima. Se muestrearon 222 porcinos de ambos sexos procedentes de establecimientos de crianza tecnificada y 218 de crianza no tecnificada, durante junioy julio del 2001. Los animales eran mayores de 4 meses de edad (Cuadro 1). 
Cuadro 1. Distribución de muestras colectadas de porcinos según grupo etáreo, sexo y sistema de crianza para el estudio de brucelosis porcina. 2002

\begin{tabular}{lccc}
\hline \multirow{2}{*}{ Grupo } & \multicolumn{2}{c}{ Procedencia } & \multirow{2}{*}{ Total } \\
\cline { 2 - 3 } & $\begin{array}{c}\text { Crianza } \\
\text { Tecnificada }\end{array}$ & $\begin{array}{c}\text { Crianza No } \\
\text { Tecnificada }\end{array}$ & \\
\hline Marranas & 53 & 09 & 62 \\
Verracos & 02 & 08 & 10 \\
Gorrinas & 87 & 114 & 201 \\
Gorrinos & 80 & 87 & 167 \\
\hline Total & 222 & 218 & 440 \\
\hline
\end{tabular}

\section{Tamaño y colección de Muestra}

El tamaño muestral fue obtenido mediante la fórmula de estimación de proporciones basada en la distribución normal para poblaciones infinitas (Daniel, 1996) empleando una prevalencia de 5.35\% (Rodríguez, 1983) con un nivel de confianza de $95 \%$ y un error máximo admisible de 3\%. Las muestras de sangre fueron colectadas en el momento del beneficio, y transportadas al Laboratorio de Virología de la Facultad de Medicina Veterinaria de la Universidad Nacional Mayor de San Marcos, donde se almacenaron a una temperatura de $-20^{\circ} \mathrm{C}$ hasta el momento de su procesamiento.

\section{Detección de anticuerpos contra Brucella sp.}

La detección de anticuerpos contra Brucella sp. se realizó por la prueba de Rosa de Bengala, prueba estándar para el diagnóstico de la brucelosis en el país, y de acuerdo al protocolo ampliamente conocido. Las muestras que resultaron positivas, fueron sometidas a confirmación de Brucella sp. mediante la prueba de Fijación de Complemento (FC).

\section{Análisis estadístico}

La frecuencia de ocurrencia de Brucella sp. se basó en resultados positivos a la prueba de Fijación de Complemento, expresándose en forma porcentual con sus respectivos intervalos de confianza (IC).

El efecto de las variables edad, tipo de crianza y sexo sobre la presencia de anticuerpos contra Brucella sp. se evaluó mediante la prueba de Regresión Logística.

\section{Resultados}

La frecuencia de brucelosis en porcinos se presenta en el Cuadro 2. En el Cuadro 3 se muestran los resultados de la prueba confirmatoria de FC en las muestras positivas $(n=21)$ a anticuerpos mediante Rosa de Bengala. La distribución de los animales reactores según sexo y título de anticuerpos fijadores de complemento se muestra en el Cuadro 4.

El análisis de regresión logística determinó que existe 3.43 (1.23 - 9.53) veces más riesgo de encontrar en los mataderos de Lima animales positivos a Brucella sp. (mediante la prueba de Rosa de Bengala) que son provenientes de granjas no tecnificadas en comparación a aquellos que provienen de granjas tecnificadas. 
Cuadro 2. Detección de anticuerpos contra Brucella sp. en porcinos procedentes de establecimientos de crianza tecnificada y no tecnificada de la zona de Lima, mediante la prueba de Aglutinación en Placa Rosa de Bengala (RB). 2002

\begin{tabular}{|c|c|c|c|c|c|c|c|}
\hline \multirow{2}{*}{$\begin{array}{l}\text { Tipo de } \\
\text { crianza }\end{array}$} & \multirow{2}{*}{ Animales } & \multirow{2}{*}{$\begin{array}{c}\text { Animales } \\
\text { positivos a } \\
\text { RB }\end{array}$} & \multicolumn{4}{|c|}{ Animales } & \multirow{2}{*}{$\begin{array}{l}\text { Frecuencia } \\
(\%) \pm 1 C^{1}\end{array}$} \\
\hline & & & Marrana & Gorrina & Verraco & Gorrino & \\
\hline Tecnificada & 222 & 5 & 2 & 1 & 0 & 2 & $2.25 \pm 1.47$ \\
\hline No tecnificada & 218 & 16 & 1 & 6 & 0 & 9 & $7.34 \pm 3.34$ \\
\hline Total & 440 & 21 & 3 & 7 & 0 & 11 & $4.77 \pm 1.81$ \\
\hline
\end{tabular}

${ }^{1}$ Frecuencia porcentual \pm intervalo de confianza

Cuadro 3. Detección de anticuerpos contra Brucella sp. en porcinos procedentes de establecimientos con crianza tecnificada y no tecnificada, mediante la prueba de Fijación de Complemento. 2002

\begin{tabular}{lccc}
\hline Tipo de crianza & $\begin{array}{c}\mathrm{N}^{\circ} \text { de animales } \\
\text { muestreados }\end{array}$ & $\mathrm{N}^{\mathrm{o}}$ de positivos & $\begin{array}{c}\text { Frecuencia } \\
(\% \pm \mathrm{IC})\end{array}$ \\
\hline Tecnificada & 222 & 0 & 0 \\
No tecnificada & 218 & 6 & $2.75 \pm 1.76$ \\
\hline Total & 440 & 6 & $1.36 \pm 0.56$ \\
\hline
\end{tabular}

${ }^{1}$ Frecuencia porcentual \pm intervalo de confianza

Cuadro 4. Titulo de anticuerpos contra Brucella sp. en porcinos de crianza no tecnificada mediante la prueba de Fijación de Complemento ${ }^{1} .2002$

\begin{tabular}{lccc}
\hline \multirow{2}{*}{ Sexo } & \multicolumn{2}{c}{ Título de anticuerpos } & \multirow{2}{*}{$N^{\circ}$ de animales } \\
\cline { 2 - 3 } & $1 / 40$ & $1 / 10$ & \\
\hline Hembras & 2 & 1 & 3 \\
Machos & 3 & 0 & 3 \\
\hline Total & 5 & 1 & 6 \\
\hline
\end{tabular}

${ }^{1}$ Prueba realizada en el Laboratorio de Sanidad Animal del Servicio Nacional de Sanidad Animal (SENASA) 


\section{Discusión}

Se pudo determinar que únicamente 6 animales dieron positivo a Brucella sp. mediante la prueba confirmatoria de FC de las 21 muestras que presentaron reacción de aglutinación a la prueba de Rosa de Bengala. Estas muestras fueron de animales provenientes de granjas no tecnificadas (Cuadros 2 y 3 ).

La prueba de aglutinación en placa de Rosa de Bengala con una sensibilidad de 99.3\% y especificidad de 73\% (FAO/OMS, 1986) es utilizada en el país como prueba tamiz para la detección de anticuerpos contra la brucelosis en bovinos, caprinos, porcinos y caninos, y es una prueba que incluso puede ser realizada en el campo. La prueba de FC posee 100 y $79 \%$ de especificidad y sensibilidad, respectivamente (FAO/OMS, 1986); y es considerada prueba oficial confirmatoria para el diagnóstico de la brucelosis. Si bien ambas pruebas detectan mayormente las IgM y en menor grado las IgG (Stevenson, 1999), la FC parece que discrimina mejor las aglutininas inespecíficas, lo que explicaría la diferencia en los resultados obtenidos por ambas pruebas.

Se reporta que algunos sueros de porcinos tienen aglutininas inespecíficas de tipo IgM que muchas veces interfieren con la sensibilidad de las pruebas serológicas (Wrathall et al., 1993). Inclusive la prueba de FC puede presentar dificultades en el diagnóstico de brucelosis porcina, pues ciertos sueros pueden interactuar con el complemento del cobayo que es uno de los reactivos de la prueba de FC, ocasionando falsos positivos (Priadi et al., 1985). En el presente estudio, la detección de títulos de anticuerpos de 1:40 en la mayoría de las muestras positivas constituye una fuerte evidencia de que los anticuerpos detectados por FC fueron anticuerpos específicos inducidos por Brucella sp. de campo (Cuadro 4).

El presente estudio demostró también que no existe relación entre la presentación de anticuerpos contra Brucella sp. y el sexo de los animales, pero debe tenerse en cuenta que en el macho, la infección por Brucella puede persistir por toda la vida del animal constituyendo un riesgo para la salud de la piara. Con respecto a la edad se encontró que los animales entre 4 y 15 semanas (gorrinos y gorrinas) fueron los mas afectados y, aunque se sabe que la susceptibilidad varía con la edad y que la frecuencia de infección es mayor en animales adultos, también se conoce que los lechones que se infectaron durante la lactancia presentan títulos máximos de aglutininas entre las 8 y 12 semanas de edad, las mismas que desaparecen a las 16 semanas (OIE, 1996).

El primer estudio serológico en Lima sobre brucelosis en porcinos reportó una prevalencia de 4.1\% (Palomino, 1953). Estudios posteriores en la misma zona indicaron prevalencias de 4.6 a $12 \%$ empleando las pruebas de aglutinación en placa y tubo (Bullón, 1959; Bazán, 1969). Los resultados obtenidos mediante la prueba de Rosa de Bengala $(4.77 \%)$ habría sido similar a lơ reportado en los previos estudios de no haberse empleado la prueba de FC. Merece mencionar que en las décadas del '50 y '60 la crianza porcina en el país estaba poco desarrollada por lo que la brucelosis era una enfermedad de mayor frecuencia. Actualmente el desarrollo de la industria porcina exige un óptimo estado sanitario, por lo que ciertas enfermedades como la brucelosis habrían sido eliminadas de las granjas tecnificadas.

La presencia de Brucella sp. en porcinos pareciera estar asociada a sistemas de crianza de escasos o deficientes niveles tecnológicos, y donde las condiciones zoosanitarias son propicias para la cadena de transmisión como lo determina el análisis de regresión logística.

\section{Agradecimiento}

Los autores agradecen al personal del Laboratorio del Servicio Nacional de Sanidad Animal (SENASA), por la realización de la prueba confirmatoria de Fijación de Complemento. 


\section{Literatura Citida}

1. Alton, G.G.; L.M. Jones; R. Angus; J.M. Verger. 1998. Techniques for the Brucellosis Laboratory. INRA. Paris, France.

2. Bazán, O. 1969. Brucelosis porcina. Encuesta serológica en los departamentos de Lima, La Libertad, Lambayeque e Ica. Tesis Fac. Med. Vet., Univ. Nac. Mayor de San Marcos. Lima. 31 p.

3. Bercovich, Z. 1998. Maintenance of Brucella abortus-Free herds: A reveiw with emphasis on the epidemiology and problems in diagnosing brucellosis in areas of low prevalence. Vet. Quart. 20: 81-88.

4. Bullón, F. 1959. Difusión de la brucelosis suina con especial referencia a la prueba del anillo en suero sanguíneo. Tesis Fac. Med. Vet., Univ. Nac. Mayor de San Marcos. Lima. 21 p.

5. Corbel, M.J. 1997. Brucellosis: an Overview. Emerg. Infect. Dis. 3: 213221.

6. Daniel, W. 1996. Bioestadística base para el análisis de las ciencias de la salud $5^{\text {ta }}$ ed. UTEHA Noriega. México. p 143155.

7. Dájer, A.; E. Gutiérrez; D. Zapata. 1997. Uso de la prueba de ELISA y aglutinación con rivanol para el diagnóstico de brucelosis en Yucatán, México. Dpto. de Producción Agrícola y Animal Universidad Autónoma Metropolitana. México. p 6.

8. FAO/OMS. 1986. Sexto Informe del Comité Mixto de Expertos en Brucelosis. Serie de Informes Técnicos 740 . Ginebra. p 149.

9. INEI, 1995. III Censo Agropecuario. Instituto Nacional de Estadística e Informática. Tomo II. p 152-203. Lima, Perú.

10. Nicoletti, P. 1980. The epidemiology of bovine brucellosis. Adv. Vet. Sci. Comp. Med. 24: 69-98.

11. Office International des Epizooties (OIE). 1996. Manual of standards for diagnosis Tests and Vaccines. p 242-255.
12. OPS. 1986. Programa de Adiestramiento en Salud Animal para América Latina. Cuarentena Animal - Enfermedades cuarentenables. Vol. 1. p 208-210.

13. Palomino. 1953. Incidencia de brucelosis en el ganado porcino sacrificado en el frigorífico nacional. Tesis Fac. Med. Vet., Univ. Nac. Mayor de San Marcos. Lima $22 \mathrm{p}$.

14. Priadi, A.; U. Chasanah; R.G. Hirst; J.J. Emmins; J. Van der Giesse; M. Soeroso. 1985. Development of an ELISA for detecting antibody to Brucella suis in porcine sera. Penyakit Hewan. 17: 66-70.

15. Ríos, M.; H. Rivera; N. Sandoval; A. Manchego; C. Camacho; R. Rosadio. 1997. Asociación del virus del Cólera Porcino con mortalidad neonatal en crianza porcina no tecnificada. Rev. Inv. Pec. 8: 10-18.

16. Rodríguez. 1983. Diagnóstico de situación de brucelosis en porcinos beneficiados en camales de Lima. Tesis Fac. Med. Vet. Univ. Nac. Mayor de San Marcos. Lima. $35 \mathrm{p}$.

17. Samartino, L. 2001. Brucelosis en Latinoamérica: Situación actual y perspectivas de control. XXIV Reunión Científica Anual Peruana de Producción Animal (APPA).

18.Sangari, F.J.; J. Agüero. 1996. Molecular basis of Brucella pathogenicity; an update. Microbiología Sem. 12: 207-218.

19. Stevenson, G.W. 1999. Common mistakes in interpretation of population serology. American Association of Swine Practitioners. Pardue University, West Lafayette, IN, USA. p 339-343.

20. Trout, D.; T.M. Gómez; B.P. Bernard; C.A. Mueller; C.G. Smith; L. Hunter; M. Kiefer. 1995. Outbreak of brucellosis at a United States pork packing plant. J. Occup. Envirom. Med. 37: 697-703.

21. Wrathall, A.E.; E.S. Broughton; K.P.W. Gill; G.P. Goldsmith. 1993. Serological reaction to Brucella species in British pigs. Vet. Rec. 132: 449-54. 